\title{
Understanding the physical, social, and emotional experiences of people with uncontrolled Type 2 diabetes: a qualitative study
}

This article was published in the following Dove Press journal:

Patient Preference and Adherence

9 November 2016

Number of times this article has been viewed

\author{
Anna Berenguera, ${ }^{1,2, *}$ Àngels \\ Molló-Inesta, ${ }^{1,3,4, *}$ Manel \\ Mata-Cases, ${ }^{1,4-6}$ Josep Franch- \\ Nadal, ${ }^{1,2,6-8}$ Bonaventura \\ Bolíbar,' Esther Rubinat, 1,9,10 \\ Dídac Mauricio ${ }^{1,11}$
}

'Scientific Department, Institut Universitar d'Investigació en Atenció Primària Jordi Gol, Cerdanyola del Vallès, Spain; ${ }^{2}$ Primary Care Department, Universitat Autònoma de Barcelona, Barcelona, Spain; ${ }^{3}$ Cervera Primary Health Care Centre, lleida, Spain; ${ }^{4}$ Diabetes Association in Primary Health Care (RedGDPS), Institut Català de la Salut, Barcelona, Spain; ${ }^{5}$ La Mina Primary Health Care Centre, Barcelona, Spain; ${ }^{6} \mathrm{CIBER}$ of Diabetes and Associated Metabolic Diseases (CIBERDEM), Barcelona, Spain; ${ }^{7}$ Raval Sud Primary Health Care Centre. Barcelona, Spain; ${ }^{8}$ Primary Health Care Department, Institut Català de la Salut, Barcelona, Spain; ' Nursery Department, Univeristat de Lleida, Lleida, Spain;

${ }^{10}$ Centro de Investigacion Biomedica en Red de Diabetes y Enfermedades Metabolicas Asociadas (CIBERDEM), Instituto de Salud Carlos III (ISCIII), Barcelona, Spain; "'Endocrinology \& Nutrition Department, CIBER of Diabetes and Associated Metabolic Diseases (CIBERDEM), Health Sciences Research Institute and Hospital Germans Trias i Pujol, Badalona, Spain

*These authors contributed equally to this work
Correspondence: Anna Berenguera Àrea científica, Institut Universitari d'Investigació en Atenció Primària (IDIAP Jordi Gol), Gran Via Corts Catalanes,

587 - àtic, 08007 Barcelona, Spain Tel +34934824425

Email aberenguera@idiapjgol.org
Purpose: The purpose of this study was to identify the perceptions, barriers, and facilitators of self-management of Type 2 diabetes mellitus (T2DM) to determine the factors to consider when developing and implementing a person-centered intervention in patients with poor glycemic control attending primary care.

Methods: This was a qualitative study conducted in 6 primary care health centers in Catalonia. Patients who had been diagnosed with T2DM and had glycated hemoglobin of $9 \%$ or more were included. The sampling method was opportunistic, accounting for gender, age, duration of diabetes, and type of treatment. Forty-three semi-structured interviews were conducted. Thematic content analysis was performed.

Results: The patients perceived the diagnosis of T2DM as a threat to their health, and the diagnosis generated cognitive and emotional representations of T2DM. The emotions associated with the diagnosis included fear of the future, worry, denial, sadness, and dejection. The patients also wondered if there could have been an error in their test results because they did not present any symptoms. These representations, both cognitive and emotional, can produce specific effects in adaptation processes and require different approach strategies, specifically regarding diet, physical activity, and pharmacological treatment. Finally, specific aspects regarding the acceptability and adaptability of the implementation of a new intervention were expressed.

Conclusion: Patients with T2DM and very poor glycemic control expressed difficulty achieving a balance between the needs and demands of managing and controlling T2DM because they felt it strongly interfered in their daily lives.

Keywords: qualitative research, interviews as a topic, Type 2 diabetes, self-management

\section{Introduction}

Type 2 diabetes mellitus (T2DM) is a chronic health condition that requires a lifelong commitment to complex lifestyle modifications involving nutrition management, a physically active lifestyle, and often regular self-monitoring of blood glucose and adherence to oral and/or injectable (insulin and GLP-1RA) treatments as well. ${ }^{1-3}$

The prevalence of T2DM in Catalonia, according to data published in 2012, is $7.6 \%$ of people between 31 and 90 years of age. According to those data, $56 \%$ of patients achieve an glycated hemoglobin (HbA1c) under 7\%, 79\% an $\mathrm{HbA} 1 \mathrm{c}$ under $8 \%$, and $5 \%$ have A1c values above $10 \%$ and are thus very far from their goals of good glycemic control. ${ }^{4}$

The chronic nature of T2DM means that adequate self-management is crucial in achieving treatment targets. Motivation for self-care is critical for improvements in glycemic control. In contrast, low adherence to treatment and poor self-management is associated with poor health outcomes, presenting a significant public health burden., 2,4 
Self-management of T2DM is physically, intellectually, emotionally and socially demanding. Maintaining behavior change is important for the effectiveness of lifestyle interventions in controlling T2DM, but it requires continual effort and the ability to adapt to changing circumstances ${ }^{7}$ Graffigna et al, studied the reasons for disengagement of diabetic patients, and the findings suggest that patients give meaning to their diabetes and its management through a complex frame of subjective experiential dimensions (cognitive/thinking, behavioral/conative and emotional/ feeling), which have an impact on the spheres of daily life crucial for the management. ${ }^{8}$

Socio-demographic and clinical characteristics alone cannot explain why some T2DM patients maintain poor metabolic control. Furthermore, a number of psychosocial factors can influence the quality of glycemic regulation. ${ }^{5}$ These include self-efficacy, personality traits, different coping capacities, various dimensions of stress, and social support, as well as the relationship between the patient and health care professionals. ${ }^{9}$ Patient adherence appeared to be directly influenced by the perceived level of health care professionals ability to motivate patients' autonomy. ${ }^{10}$ Family support is another issue that can influence self-management, a study done in 17 countries showed the experiences of family members who support adults living with diabetes: worries about hypoglycemia, employment, how the diabetes negatively affects the relationship and the help of the family member to make positive life changes for their health. ${ }^{11,12}$

The most commonly reported barriers among patients with T2DM are a lack of understanding of the overall care plan, and frustration with inadequate metabolic control and disease progression despite compliance with selfcare recommendations. ${ }^{13}$ A systematic review found that resource availability is an important barrier to effective self-management. However, many barriers to improving care are amenable to behavior change strategies. Improvement strategies need to account for the differences between clinical targets and tailored rather than "one size fits all" approaches need to be considered. ${ }^{2}$ Other findings highlight the differences in the needs and challenges of T2DM self-management among men and women, which may inform gender-sensitive T2DM care, counseling and support. ${ }^{14}$

Some studies report that the involvement of primary health care professionals, including their relationship and communication with patients with consistently poor metabolic control can influence health parameters in general. ${ }^{15-18}$

The diagnosis of diabetes produces a stressful situation, and faced with this type of disease, the resulting cognitive processes can be framed within different theoretical models. This study has been framed within Leventhal's common sense self-regulation framework. ${ }^{19}$ This framework is characterized by a dynamic model that considers persons as active "solvers" of their health problems. Individuals perceive a threat to their health as a result of a symptom or a diagnostic test and create cognitive and emotional representations. These representations lead to attempts at regulation by means of approach strategies or plans of action, and finally, the individuals assess the consequences of these actions and regulate their response in successive episodes through a system of continuous feedback.

For the design of complex interventions to address T2DM, the cooperation of health care users is considered crucial. In-depth knowledge of the context it is essential for implementing interventions. Taking into account that the discourses of people living with diabetes can be instrumental in increasing the motivation for participating in the study, it can contribute to strategies to facilitate recruitment and also to the adherence of health care users. ${ }^{17-19}$ It can also enhance acceptability, sustainability and adaptation of the intervention in each context. In addition, cultural sensitivity and social significance of the intervention for the target population increases the probability of positive changes and of translation of the results into real life.

A complex intervention (INTEGRA) for people living with T2DM was planned. The aim of INTEGRA was to determine whether glycemic control, measured by the average concentration of $\mathrm{HbA} 1 \mathrm{c}$ of patients with poorly controlled T2DM, improves when they are evaluated and treated in the primary care environment with an integrated strategy (Table 1 - INTEGRA intervention components).

The objective of this study was to identify the perceptions, barriers, and facilitators of T2DM self-management expressed by patients seen in the primary care setting in our region to determine the factors that could be accounted for

Table I INTEGRA intervention components

\begin{tabular}{ll}
\hline Intervention group I & Intervention group 2 \\
\hline $\begin{array}{l}\text { A monographic consultation carried } \\
\text { out by a doctor and a nurse that } \\
\text { will provide the participant a full }\end{array}$ & \\
assessment of their case & \\
Basic training in clinical & Basic training in clinical \\
practice guidelines & practice guidelines \\
Training of professionals in & Training of professionals in \\
coaching & coaching \\
Intervention based on patients' SMS & Intervention based on \\
phone messages & patients SMS phone messages \\
\hline
\end{tabular}


when developing and implementing an intervention strategy focused on individuals with very poor glycemic control.

\section{Methods \\ Methodology}

A qualitative methodology to study perceptions, barriers, and facilitators of individuals with poorly controlled T2DM, based on personal experiences and daily life events, was conducted.

\section{Setting}

The study was conducted in 6 health care centers in three of the four geographical provinces of Catalonia. Two centers participated in Girona, Lleida and in Barcelona.

In Spain, patients with Type 2 diabetes are mainly cared for by primary care professionals, which together with the gatekeeping role played by Spanish general practitioners (general practitioners and nurses), means that the information available from primary care is very comprehensive. The objective of continuous and systematic therapy education (diet, physical activity) is to train patients on self-management by means of appropriate educational programs, to adapt the treatment to their own disease and to enable them to perform their daily activities.

\section{Participants}

We sought the participation of individuals who were diagnosed with T2DM and had an HbA1c of $9 \%$ or higher in their most recent test performed in the 12 months prior to the study, which was the principal inclusion criterion of the intervention study.

\section{Sampling}

The sampling for the study was opportunistic. ${ }^{20}$ Despite not being a theoretical sample, it took into account the following variables: gender, age, years of progression of T2DM, and type of treatment (oral antidiabetics, insulin, or a combination). An informative richness for a deeper understanding of the phenomenon was achieved. ${ }^{20}$

\section{Recruitment strategies}

At each primary care center, a liaison person was selected to facilitate the communication between the center and the research team. One member of the research team contacted the liaison person at each primary care center. These liaison persons, together with the primary care professionals, identified the patients who met the criteria of poor glycemic control and contacted the potential participants.

\section{Techniques for gathering information}

Semi-structured individual interviews were used to obtain the information. This interview technique is especially useful when it is important to collect the subjective opinions of societal actors, and is even more valuable when wanting to explore diverse points of view that represent the different attitudes that might exist regarding the subject of investigation. ${ }^{21}$ Forty-three interviews with 20 women and 23 men were conducted. The interviews lasted 45-60 minutes and took place in the primary care centers. The interviews were audio-recorded and subsequently transcribed systematically and verbatim. All the interviews were moderated by the same technical expert from the research team. The topic guide for the interviews can be seen in Table 2 .

\section{Analysis}

A thematic content analysis was performed based on the information obtained in the interviews. ${ }^{22}$ The data were analyzed in the following manner: after successive readings of the transcribed interviews, ${ }^{23}$ the researchers attained some pre-analytical insight into the data. Next, four researchers conducted the following analytical steps: a) identification of the relevant subjects and texts; b) fragmentation of the text into units of meaning; c) text codification with a mixed strategy: Leventhal model and emerging codes from the data; d) creation of categories by grouping the codes based on the criterion of similarity; e) analysis of each category; and f) elaboration of new text with the results. These results were subsequently discussed among the research team members until a consensus was reached (triangulation). The analysis was done using NVivo.

\section{Ethical aspects}

This study was conducted according to the Declaration of Helsinki and Good Clinical Research Practice. Participants signed informed consent forms at the beginning of each interview. The confidentiality and anonymity of the data were ensured through a pseudonym chosen by each informant. This name was used to identify the transcriptions and the selected verbatim transcripts. The project was approved by the Ethics Committee of the Jordi Gol Institute of Research in Primary Care (P14/129).

\section{Results}

The characteristics of the 43 interviewees are provided in Table 3. An interpretative analysis of the thematic content was performed, following text codification with a mixed strategy involving Leventhal's model and emerging codes from the data. The category structure could be seen in Figure 1. 
Table 2 Interview guide for interviewing patients

\section{Target population interviews}

How did your life change when you were diagnosed with diabetes?

Describe your experiences with the control and treatment of diabetes

in the past year

- Diet and nutrition

- Physical activity

- Pharmacological adherence

- Managing stress and worry

- Symptoms and complications

- Care received

- Blood pressure control

How would you describe your control and care in relation to diabetes? What were the chief complications you experienced in relation to diabetes in the past year?

- Diet (family events, trips, watching what you eat)

- Personal life

- Treatment

- Hyper- or hypoglycemia

- Fears and worries about complications

- Late complications (such as eyes, kidneys, feet, infarction, stroke, amputations)

- Fears and worries about complications

Specific aspects of managing medications

- Do you sometimes have problems taking your medication?

- To what do you attribute these problems? (economic, medical, personal, treatment factors, etc.)

- How do you attempt to overcome these problems?

- Do you currently use any system that helps you control your medication?

What type of assistance or resources have been most helpful for controlling diabetes?

- Family and friends

- Primary care professionals

- Websites

- Documentation

Describe your experience during your most recent visit to the primary care center

- Experience with the family physician

- Messages of advice from the primary care professionals How do you think you can improve control of your diabetes? What do you think your primary care center should improve about controlling the disease?

- Primary care professionals

- Pharmacy offices

- More resources to consult for control of the disease

- Specialists

Specific aspects of acceptability, adaptability of the intervention

Basic ICT competencies and their possible utilization

- Do you have a mobile phone to use for regular communication? Do you use an instant messaging system or Whatsapp?

- Do you have a computer with which you can navigate the Internet?

- Do you use the Internet to find specific information that interests you?

- Do you use the Internet as a means of communication to talk with your friends, family members or other persons (chats, forums, etc.)?

- Would you like to receive informative or advice on your disease by mobile phone or on the Internet?

Abbreviation: ICT, information and communications technology.

\section{Leventhal framework}

\section{External stimulus: diagnosis of T2DM}

The patients explained that they were diagnosed with T2DM after experiencing a symptom or as a result of a diagnostic test, and they perceived this diagnosis as a threat to their health.

The way the diagnosis was delivered influenced the manner in which the individual self-managed the disease. The participants related that in many cases, the communication of the diagnosis was brusque and that they asked few questions at that time because they felt a mental block from the impact of the diagnosis.

They also related some good experiences with communication in cases in which the primary care professional remarked that the treatment was simple and that they could lead a normal life following some changes in their daily habits.

As a result of the diagnostic test (external stimulus), the patients developed cognitive and emotional representations of T2DM. These two representations mutually influenced each other.

I remember they called me at home, and they said, 'come to the appointment right now.' When I arrived at the primary care center, they told me, 'you have Type 2 diabetes'.

\section{The cognitive representation the participants create comprises different components}

Identity: the participants knew what diabetes was and explained very well the symptoms for which they visited the primary care professionals because they noticed changes within their bodies.

I noticed I felt extremely tired and was sweating [...] and

I just felt like drinking water.

Cause or attribution of the disease: it reassured most of the participants to think that the cause of their diabetes was related to a genetic predisposition and that, to some extent, they were exempted from feeling guilty about having the disease. They also argued that the presence of some stressful life event (an operation, death of a family member, family misfortunes) triggered the disease. Only four participants attributed the disease to poor self-control, "carelessness", or an unhealthy lifestyle. Two participants reported having no idea about what the origin of their T2DM could be.

My mother had diabetes, my grandmother too; I've always lived with this disease [...] I don't know [...] it's like it's part of the family $[\ldots]$ I knew that it would end up happening to me like the rest of the family. 
Table 3 Socio-demographic characteristics of interviewees

\begin{tabular}{|c|c|c|c|c|}
\hline Region & Gender & Age, years & Type of treatment & Origin \\
\hline \multirow[t]{5}{*}{ Lleida } & 7 women & 2 aged $30-39$ & 6 on oral antidiabetic drugs & 2 Africans \\
\hline & 9 men & 2 aged $40-49$ & 10 on insulin + oral antidiabetic drugs & I4 Native-born \\
\hline & 16 in total & 5 aged $50-59$ & & \\
\hline & & 4 aged $60-69$ & & \\
\hline & & 3 aged $70-80$ & & \\
\hline \multirow[t]{5}{*}{ Girona } & 7 women & 2 aged $30-39$ & 4 on oral antidiabetic drugs & 4 Africans \\
\hline & 6 men & 2 aged $40-49$ & 9 on insulin + oral antidiabetic drugs & 9 Native-born \\
\hline & 13 in total & 3 aged $50-59$ & & \\
\hline & & 3 aged $60-69$ & & \\
\hline & & 3 aged $70-80$ & & \\
\hline \multirow[t]{5}{*}{ Barcelona } & 6 women & I aged 30-39 & 3 on oral antidiabetic drugs & 2 South Americans \\
\hline & 7 men & 3 aged $40-49$ & 10 on insulin + oral antidiabetic drugs & 3 Africans \\
\hline & 13 in total & 3 aged $50-59$ & & 8 Native-born \\
\hline & & 3 aged $60-69$ & & \\
\hline & & 3 aged $70-80$ & & \\
\hline
\end{tabular}

Duration: the participants said that diabetes was a chronic disease that kills slowly, silently and painlessly as a consequence of its complications.

Nothing hurts, but I go to the doctor and they tell me $[\ldots]$ your gly $[\ldots]$ or whatever it's called [...] is getting worse all the time [...] it's a disease that kills you with its complications.

Consequences: the patients mentioned cardiovascular complications but stated that they felt their condition was well-controlled by the primary care professionals. They had scheduled visits (ophthalmological, foot, and cardiovascular checkups, laboratory tests, etc.) to mitigate the possible complications of the disease. They expressed that hypoglycemia was a consequence of T2DM and that they learned to "listen" to their body to prevent hypoglycemia from occurring. They stated that they were experts in balancing their medication, diet and exercise to prevent it.

In the primary care center, I'm treated very well [...] if you control this, that $[\ldots]$ the only thing the doctor can't do is control the medication.

Control of the disease: the main difficulty they reported was gaining control of the disease (based on laboratory tests). They attributed this lack of control to not finding the appropriate drug for regulating the glycemia (external locus). Four patients blamed themselves for not having followed the recommended diet or for not getting enough physical activity (internal locus) and affirmed that this had a negative repercussion on the control of their disease. All the participants knew that diabetes was an incurable chronic illness. Some commented that they had already lived with the disease and that they knew how to control it.

Leventhal's model proposes that the elements mentioned earlier, together with the emotional response, determine both the manner of understanding and the meaning given to the health-related information, as well as how the individual adjusts to that information. Consequently, the individuals generate emotional and cognitive representations of the disease.

\section{Emotional representation}

The emotions associated with the disease included fear about the future, worry, denial, sadness, and dejection. The participants also wondered whether there might have been an error in the test results because they did not feel pain.

These representations, both cognitive and emotional, can produce specific effects on a patient's adjustment to and tackling of a disease, but they are not necessarily independent of each other.

The future terrifies me; I remember my grandfather had a leg amputated and my mother ended up half blind.

\section{Cognitive and emotional approach strategies associated with diabetes control}

Strategies for approaching one's diet: the patients stated that the most substantial change was not being able to eat certain prohibited items. Since their T2DM diagnosis, they felt a stronger desire to eat these foods. Some said that they had attempted to compromise regarding excessive or inappropriate caloric intake and that they only worried about 


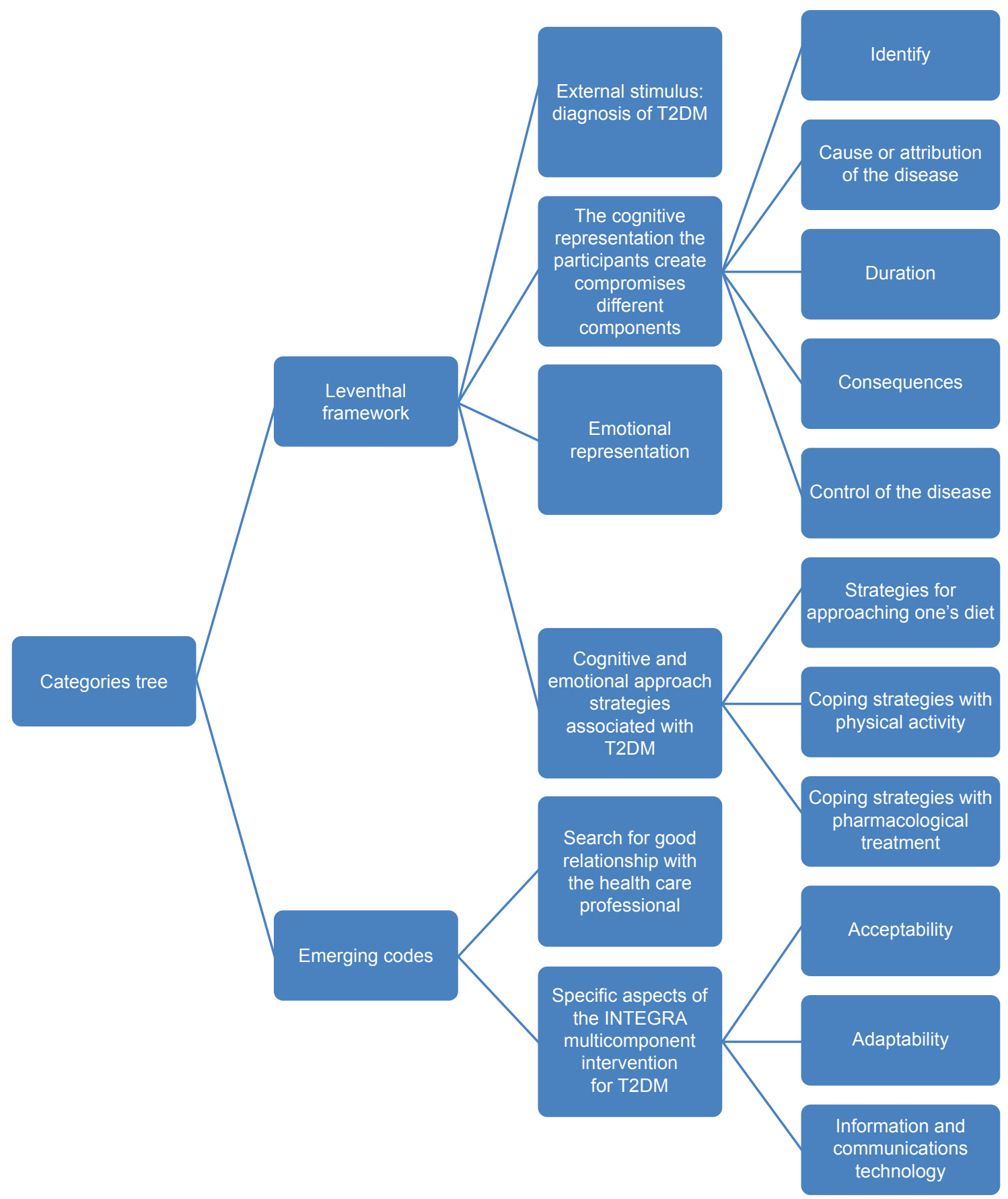

Figure I Categories tree figure.

Abbreviation: T2DM, Type 2 diabetes mellitus.

not overindulging in sweets and not eating carbohydrates in excess. Others expressed strictly following the diet proposed by the primary care professionals, but when they explained it in detail, they included prohibited foods or foods that were not recommended. When they referred to these foods, they always indicated small amounts with their hands. Discordance was observed between their verbal and nonverbal communication.
They felt that the diets usually recommended at office visits were not individualized or personalized and were difficult to implement. The economic difficulty in following these diets was also perceived as a limiting factor, particularly in the immigrant population. Patients who were immigrants experienced many difficulties in adjusting to the changes in diet, such as reducing their consumption of carbohydrates. 
They often discovered the best foods for their physical condition by using the glycemic control results from test strips. The participants were annoyed by the limitations in using test strips as a result of economic barriers.

They stated that the type of food they were prescribed was highly restrictive and difficult to implement in their daily lives. The participants said that members of their immediate families who had diabetes were not controlled so extensively and that these relatives had managed to live a long time without complications. The women indicated that it was very complicated to follow the recommended diet because of their role as caretakers. Many of them had to prepare meals for their families or grandchildren and ended up eating a smaller amount of what they cooked for the rest of the family. Caring for others was more important to them than their own needs in regards to food. Some of them attempted to compensate for these imbalances by engaging in more physical activity.

I know what I have to eat, but sometimes I can't spend so much money to eat right. That is the problem [...] And that's what people don't understand.

I have three children, when I get home after work, I fix a meal for them [...] I'm so tired from working all day that I end up eating the same food as they do.

\section{Physical activity coping strategies}

All the participants attributed beneficial effects to physical activity, although they did not have a clear understanding of its effects on hyperglycemia. Most of them admitted that they did not engage in any regular physical activity, despite being aware of its benefits. Many women interviewed said that they performed physical activities while cleaning the house or shopping. That was considered a fulfillment of physical activity, and thus they believed that they had already covered that aspect. Some patients mentioned that they could not participate in any physical activity because of their comorbidities.

I usually go out in the morning to buy a few things, but then I stay at home sewing all afternoon.

\section{Pharmacological treatment coping strategies}

With regard to pharmacological treatment, many believed that good control of diabetes was defined only by taking the drug as prescribed by the physician. Individuals treated with insulin explained that in specific situations, they modified their medication intake, increasing the dose as a way to compensate for eating forbidden foods.
The patients felt more or less "diabetic" depending on the type of treatment they were prescribed. They attributed treatment with insulin to more serious diabetes. They thought that beginning insulin treatment was the most difficult step to take, but once they overcame the fear of being stuck with a needle, they saw that the treatment improved their quality of life.

Ooh [...] I don't want to start on insulin [...] I'd rather take a thousand pills than stick myself [...] that means you're really sick now. With metformin [thinks about it a lot, and this is the way it was finally said], the thing is, it gives me a lot of diarrhea $[. .$.$] but I don’t want to stick myself for anything.$

\section{Emerging codes}

Search for support and a good relationship with the health care professional

In general, the participants were satisfied with their check-ups at the primary care centers where they were seen. Regarding aspects needing improvement, they proposed improvements in communication and in the professional-patient relationship. Some participants commented that there was a lack of empathy and understanding of patients' problems, which was attributed to the short time allowed for the consultation. They related this lack of time to cutbacks caused by the economic crisis. They mentioned that there was little individualization of treatments and that the same pattern was often applied to all patients.

They also explained that at times, the visits became an "interrogation" of the patient to identify what they have not done correctly but that there was not enough time to discuss their worries, fears, and possible complications of the disease. Few patients recalled the health care professionals reassuring them. On some occasions, they felt that they were scolded and blamed. Additionally, they commented that it would be necessary for them to occasionally be referred to a health care specialist (endocrinologist).

The office visit consists of talking about the test results and telling me that I'm not following the diet or exercising, for example, I'd like to talk about other concerns [...] ask them if all this can cause sexual dysfunction, but they look so rushed that I don't ask.

\section{Specific aspects of the INTEGRA intervention regarding acceptability, adaptability, and information and communications technology (ICT)}

The patients stated that participating in this study was an opportunity for them, and they wanted to actively collaborate 
in scientific progress. They thought that the study could improve the way the disease was addressed and thus achieve a deeper understanding of T2DM. All of them agreed to participate in a future study and wanted to be promptly informed about the results.

They said that the schedules and days of the intervention should be adjusted to accommodate their work and family needs.

The use of new technologies did not worry them, and they mentioned that a trusting relationship with primary care professionals was essential and that no ICT could replace this. Mobile phones were part of their lifestyles, and they wanted to receive personalized information by SMS on how to improve their healthy behavior. With the exception of the youngest participants, the majority stated they did not consult any websites because they already knew what there was to know about their disease.

I want to participate in anything that helps cure my disease

[...] it's doing a good thing, right?

It would be good if there was a group for people who work in the morning or late; I'm retired, but I also have my things to do.

I prefer face-to-face contact [...] but SMS messages, yes, I read them.

\section{Discussion}

\section{Summary of the main results}

In this study, individuals with a diagnosis of diabetes who had poor glycemic control identified a wide variety of strategies to manage their disease. Controlling the disease on their own (self-management) should occur daily, but this was often difficult due to family or economic reasons, a lack of awareness, or a lack of motivation. They thought of themselves as the ones who understood their disease best. Even so, they commented that controlling the disease was based on pharmacological adherence, which was part of the health care professional's job. The participants said that they learned to compensate for foods and to address small day-to-day problems and that at times, they even made treatment-related decisions. They thought that self-management of the disease (adapting to all the changes in lifestyle and finding the best drug to achieve glycemic control) was difficult.

\section{Principal results and comparison to scientific evidence}

Most of the diabetic patients stated they did not properly follow the recommended diet. Adherence to the diet was even worse among immigrant patients due to cultural and socio-economic barriers. A lack of adherence is a common problem in chronic pathologies such as diabetes, with public health and economic repercussions. A good physician-patient relationship and effective channels of communication, as well as shared decision making, are key to facilitating the patients' understanding of their pathology and treatment. ${ }^{24,25}$ Knowledge of the reasons motivating patients to not follow the recommended lifestyle and pharmacological changes allows us to select strategies appropriate for each patient to improve their control of Type 2 diabetes. ${ }^{9,25}$

In our study, we observed differences between native-born patients and immigrants in following the prescribed diet. This is probably due to the patients' beliefs regarding the disease, ${ }^{27}$ as well as the typical diet inherent to each culture ${ }^{28}$ and the carbohydrate content distinguished in the Mediterranean diet with respect to other diets. Patient ethnicity also has an influence on glycemic control. ${ }^{26}$ Understanding patients' beliefs and cultural background will help health care professionals determine their treatment plan. The patient and the physician must work together to design a plan and thus achieve the desired result. To gain better control of a disease, the patient must be involved in the decision making, taking into account the communication problems (language barriers) that can contribute to reducing the impact of the health care professional's recommendations. ${ }^{27}$

The patients interviewed in our study said that the treatment recommendations should be individually tailored to the patient's needs and sociocultural and economic situation during the office visits. This request is consistent with a person-centered approach. ${ }^{28,29}$ In various studies, ${ }^{30,31}$ it has been demonstrated that a good perception of personcentered chronic illness care by patients with T2DM is associated with better levels of self-management, improved empowerment, and consequently, better glycemic control. Individualized patient care can also help empower patients to adjust their pharmacological treatment when they change their routine physical activity or when they do not adhere to the recommended diet.

Additionally, the participants were aware that their lack of glycemic control could be due to the limitations of the use of test strips, which they attributed to the economic crisis. The adaptation of the Catalan Health Institute to use test strips is not attributed exclusively to economic motives, but to the inefficiency of glucose self-monitoring shown by several studies in patients treated only with diet or oral antidiabetic drugs. ${ }^{13,32}$

The results of our study are consistent with those of Hassan et al, who found that patients associate the seriousness 
of the disease with injectable treatments. This can be due to the fact that many health care professionals recommend insulin treatments because it represents the last option in the case of failure with other treatments. ${ }^{36}$ It is important to stress to patients that the switch to treatment with insulin is also related to the natural progression of T2DM itself, to prevent some patients from feeling personal failure. Exploring patients' concerns and beliefs about T2DM and insulin is crucial to assist physicians in delivering patientcentered care.

T2DM is a paradigmatic chronic condition, and those affected have a greater burden of multimorbidity than other chronic patients. Multimorbidity is a complex phenomenon that we do not yet fully understand how to manage effectively in clinical practice. ${ }^{29}$

Increased focus on the patient's role in medication intensification may provide greater insight and lead to more effective solutions to the problem of clinical inertia. ${ }^{30}$

\section{Strengths and limitations}

A strength of this research is that it delves into patient perspectives before beginning a complex intervention. This participative strategy is essential for the design and implementation of a complex intervention that is acceptable, adequate, feasible, and integrated within other programs' location, schedule, and duration. This paper corresponds to phase 1 or the modeling phase of the Medical Research Council framework. The results of the current study were used to complete the design of the INTEGRA study intervention, with the goal of improving the control of T2DM.

The rigorous procedures used (triangulation of analysis, achieving data saturation, description of the context and reflexivity, etc.) ensure the validity of the findings in our setting. Caution is needed before transferring these results to other settings. However, the similarity with other studies suggests its applicability. ${ }^{31}$ In the results, the least represented narrative was that of patients in the 30-40 age group. These patients are the ones who did not attend the interviews for reasons related to their work (even when offered different times), and it is thus necessary to study this group in other studies.

\section{Implications and/or recommendations that summarize how the findings can be applied to the practice of diabetes education}

Therefore, the results and the evidence obtained in this study were useful for modeling and designing the INTEGRA study intervention. This contributed to the design of a flexible, dynamic intervention, adapted to the participants and to the context, and facilitated an adequate implementation in the different primary health care centers.

With respect to the beliefs and opinions of the patients in this study, it will also be of interest to produce recommendations and design strategies for improving the manner of addressing treatment of T2DM in patients with persistent poor control and who are far from reaching therapeutic goals, as is the case of the population studied for the purpose of improving their glycemic control.

It is necessary as health care professionals, to investigate the causes of poor control when suggesting needed changes related to the treatment plan in order to obtain better results in control and to periodically check for compliance with pharmacological and non-pharmacological recommendations proposed for treatment of T2DM.

\section{Acknowledgments}

We thank all persons who agreed to participate. We also thank all the key informants in each primary health care center for facilitating the recruitment strategy. CIBER of Diabetes and Associated Metabolic Diseases (CIBERDEM) is an initiative included in Plan Nacional de I+D+I and cofinanced by Instituto de Salud Carlos III-Subdireccion General de Evaluación and Fondo Europeo de Desarrollo Regional (FEDER). We would like to thank Enriqueta Pujol-Ribera for valuable comments regarding the entire manuscript.

\section{Author contributions}

$\mathrm{AB}, \mathrm{AM}, \mathrm{MM}, \mathrm{ER}$ and $\mathrm{DM}$ conceived and designed the study and also contributed to the acquisition of data; $\mathrm{AB}$ conducted the interviews and the analysis and interpretation of data; all of the authors contributed toward data analysis, drafted the article or revised it critically for important intellectual content, and provided final approval for the version to be published.

\section{Disclosure}

The study was financially supported by Sanofi. The authors report no other conflicts of interest in this work.

\section{References}

1. Health Quality Ontario. Behavioural interventions for type 2 diabetes: an evidence-based analysis. Ont Health Technol Assess Ser. 2009 9(21):1-45.

2. Rushforth B, McCrorie C, Glidewell L, Midgley E, Foy R. Barriers to effective management of type 2 diabetes in primary care: qualitative systematic review. Br J Gen Pract. 2016;66(643):e114-e127.

3. Gucciardi E, Fortugno M, Horodezny S, et al. Will Mobile Diabetes Education Teams (MDETs) in primary care improve patient care processes and health outcomes? Study protocol for a randomized controlled trial. Trials. 2012;13:165. 
4. Lin EH, Katon W, Von Korff M, et al. Relationship of depression and diabetes self-care, medication adherence, and preventive care. Diabetes Care. 2004;27(9):2154-2160.

5. Vahatalo M, Ronnemaa T, Viikari J. Factors affecting the efficacy of starting insulin treatment in Type 2 diabetic patients. A retrospective evaluation. Scand J Prim Health Care. 2003;21(4):230-236.

6. Greene J, Hibbard JH, Sacks R, Overton V, Parrotta CD. When patient activation levels change, health outcomes and costs change, too. Health Aff (Millwood). 2015;34(3):431-437.

7. Hinder S, Greenhalgh T. "This does my head in”. Ethnographic study of self-management by people with diabetes. BMC Health Serv Res. 2012;12:83.

8. Graffigna G, Barello S, Libreri C, Bosio CA. How to engage type-2 diabetic patients in their own health management: implications for clinical practice. BMC Public Health. 2014;14:648.

9. Ortiz M, Ortiz E, Gatica A, Gómez D. Psychosocial Factors Associated with Adherence to Treatment of Type 2 Diabetes Mellitus. Terapia psicológica. 2011;29(1):5-11.

10. Graffigna G, Barello S, Bonanomi A, Menichetti J. The Motivating Function of Healthcare Professional in eHealth and mHealth Interventions for Type 2 Diabetes Patients and the Mediating Role of Patient Engagement. J Diabetes Res. 2016;2016:2974521.

11. Menendez Torre E, Orozco Beltran D. Percepciones de pacientes y profesionales sanitarios sobre la calidad de la atención a diabéticos en España: resultados del estudio Diabetes Attitudes, Wishes and Needs 2 [Perceptions of patients and health professionals about the quality of diabetes care in Spain: Results of the study Diabetes Attitudes, Wishes and Needs 2]. Aten Primaria. 2016;48(2):136-137. Spanish.

12. Stuckey HL, Mullan-Jensen C, Kalra S, et al. Living with an adult who has diabetes: Qualitative insights from the second Diabetes Attitudes, Wishes and Needs (DAWN2) study. Diabetes Res Clin Pract. 2016; 116:270-278

13. Nagelkerk J, Reick K, Meengs L. Perceived barriers and effective strategies to diabetes self-management. J Adv Nurs. 2006;54(2):151-158.

14. Mathew R, Gucciardi E, De MM, Barata P. Self-management experiences among men and women with type 2 diabetes mellitus: a qualitative analysis. BMC Fam Pract. 2012;13:122.

15. Bandura A. Self-efficacy: the exercise of control. New York: W. H. Freeman; 1997.

16. Drewelow E, Wollny A, Pentzek M, et al. Improvement of primary health care of patients with poorly regulated diabetes mellitus type 2 using shared decision-making - the DEBATE trial. BMC Fam Pract. 2012;13:88.

17. Nakahara R, Yoshiuchi K, Kumano H, Hara Y, Suematsu H, Kuboki T. Prospective study on influence of psychosocial factors on glycemic control in Japanese patients with type 2 diabetes. Psychosomatics. 2006; 47(3):240-246.

18. Whittemore R, D’Eramo Melkus G, Grey M. Metabolic control, self-management and psychosocial adjustment in women with type 2 diabetes. J Clin Nurs. 2005;14(2):195-203.
19. Petrie J, Weinman JA. Perceptions of Health and Illness. Current Research and Applications. Amsterdam: Overseas Publishers Association; 1997.

20. Marshall MN. Sampling for qualitative research. Fam Pract. 1996;13(6): 522-525.

21. Berenguera A, Fernández de Sanmamed MJ, Pons M, Pujol E, Rodríguez D, Saura S. Escuchar, observar y comprender. Recuperando la narrativa en las Ciencias de la Salud. Aportaciones de la investigación cualitativa [Listen, observe and understand. Reclaiming the narrative in Health Sciences. Contributions of qualitative research]. Barcelona: Institut Universitari d'Investigació en Atenció Primària Jordi Gol (IDIAP J. Gol), 2014. Available from: https://saludcomunitaria.files. wordpress.com/2014/12/escucharobservarcomprender.pdf. Accessed October 18, 2016. Spanish.

22. Pope C, Ziebland S, Mays N. Qualitative research in health care. Analysing qualitative data. BMJ. 2000;320(7227):114-116.

23. MacLean LM, Meyer M, Estable A. Improving accuracy of transcripts in qualitative research. Qual Health Res. 2004;14(1):113-123.

24. Garcia-Perez LE, Alvarez M, Dilla T, Gil-Guillen V, Orozco-Beltran D. Adherence to therapies in patients with type 2 diabetes. Diabetes Ther. 2013;4(2):175-194.

25. Janes R, Titchener J, Pere J, Pere R, Senior J. Understanding barriers to glycaemic control from the patient's perspective. J Prim Health Care. 2013;5(2):114-122.

26. Freeman J, Loewe R. Barriers to communication about diabetes mellitus. Patients' and physicians' different view of the disease. J Fam Pract. 2000;49(6):507-512.

27. Torenholt R, Varming A, Engelund G, et al. Simplicity, flexibility, and respect: preferences related to patient education in hardly reached people with type 2 diabetes. Patient Prefer Adherence. 2015;9:1581-1586.

28. Wenger A, Mischke C. "Bisschen Schweiz, bisschen Kosovo". Erleben von Schweizer Migranten mit Diabetes mellitus Typ 2 aus dem ehemaligen Jugoslawien: Eine qualitative Studie in Anlehnung an die Grounded Theory ["A Little Bit of Switzerland, a Little Bit of Kosovo". Swiss Immigrants from Former Yugoslavia with Type 2 Diabetes. A Qualitative Study' in Analogy to Grounded Theory]. Gesundheitswesen. 2015;77(10):736-741. German.

29. Bower P. Better management of multimorbidity: a critical look at the 'Ariadne principles'. BMC Med. 2014;12:222.

30. Grant R, Adams AS, Trinacty CM, et al. Relationship between patient medication adherence and subsequent clinical inertia in type 2 diabetes glycemic management. Diabetes Care. 2007;30(4):807-812.

31. Tong A, Sainsbury P, Craig J. Consolidated criteria for reporting qualitative research (COREQ): a 32-item checklist for interviews and focus groups. Int J Qual Health Care. 2007;19(6):349-357.

32. Beverly EA, Hultgren BA, Brooks KM, Ritholz MD, Abrahamson MJ, Weinger K. Understanding physicians' challenges when treating type 2 diabetic patients' social and emotional difficulties: a qualitative study. Diabetes Care. 2011;34(5):1086-1088.
Patient Preference and Adherence

\section{Publish your work in this journal}

Patient Preference and Adherence is an international, peer-reviewed, open access journal that focuses on the growing importance of patient preference and adherence throughout the therapeutic continuum. Patient satisfaction, acceptability, quality of life, compliance, persistence and their role in developing new therapeutic modalities and compounds to optimize
Dovepress

clinical outcomes for existing disease states are major areas of interest for the journal. This journal has been accepted for indexing on PubMed Central. The manuscript management system is completely online and includes a very quick and fair peer-review system, which is all easy to use. Visit http://www. dovepress.com/testimonials.php to read real quotes from published authors. 